\title{
Curcumin inhibits hypoxia-induced angiogenesis via down-regulation of HIF-1
}

\author{
MOON-KYOUNG BAE ${ }^{2}$, SE-HEE KIM ${ }^{1}$, JOO-WON JEONG ${ }^{1}$, YOU MIE LEE ${ }^{4}$, \\ HAE-SUN KIM ${ }^{1}$, SU-RYUN KIM ${ }^{2}$, IL YUN ${ }^{2}$, SOO-KYUNG BAE ${ }^{3}$ and KYU-WON KIM ${ }^{1}$ \\ ${ }^{1}$ Research Institute of Pharmaceutical Sciences, College of Pharmacy, Seoul National University, Seoul 151-742; \\ ${ }^{2}$ College of Dentistry, and ${ }^{3}$ College of Medicine, Pusan National University, Busan 602-739; ${ }^{4}$ School of \\ Life Sciences \& Biotechnology, Kyungpook National University, Daegu 702-701, Korea
}

Received November 24, 2005; Accepted January 5, 2006

\begin{abstract}
Hypoxia-inducible factor-1 (HIF-1) has a central role in cellular responses to hypoxia, including the transcriptional activation of a number of genes involved in angiogenesis in tumors. We found that curcumin, a natural, biologically active compound isolated from the commonly used spice turmeric, significantly decreases hypoxia-induced HIF-1 $\alpha$ protein levels in HepG2 hepatocellular carcinoma cells. Moreover, curcumin suppressed the transcriptional activity of HIF-1 under hypoxia, leading to a decrease in the expression of vascular endothelial growth factor (VEGF), a major HIF-1 target angiogenic factor. Curcumin also blocked hypoxia-stimulated angiogenesis in vitro and down-regulated HIF-1 $\alpha$ and VEGF expression in vascular endothelial cells. These findings suggest that curcumin may play pivotal roles in tumor suppression via the inhibition of HIF- $1 \alpha$-mediated angiogenesis.
\end{abstract}

\section{Introduction}

The process of tumor progression is characterized by rapid cellular growth accompanied by alterations of the microenvironment of the tumor cells (1). The critical changes in the cellular microenvironment are due to an inadequate oxygen supply and the resultant hypoxia (2). The hypoxic tumor environment results in aggressive and metastatic cancer phenotypes that are associated with resistance to radiation therapy, chemotherapy, and a poor treatment outcome $(3,4)$. Hypoxia detected in the central regions of solid tumors can be a leading cause of angiogenesis, a fundamental determinant of malignant tumor progression, by activating the expression of angiogenic factors $(5,6)$. A key factor in this process is hypoxia-inducible

Correspondence to: Dr K.-W. Kim, College of Pharmacy, Seoul National University, Seoul 151-742, Korea

E-mail: qwonkim@plaza.snu.ac.kr

Key words: curcumin, HIF-1 $\alpha$, VEGF, angiogenesis factor (HIF), which regulates transcription of hypoxia-activated genes and consists of HIF- $1 \alpha$ and HIF-1ß heterodimer. The $\alpha$ subunit of HIF-1 is rapidly degraded under normoxic conditions and stabilized under hypoxia, while HIF-1B is expressed constitutively (7).

Curcumin, a major active component of dietary spice turmeric and the yellow pigment in curry powder, has been widely used in traditional medicine for the treatment of inflammation and diseases (8). Also, curcumin is known to have diverse biological functions, such as anti-tumor, antioxidative, anti-bacterial and anti-hepatotoxic activities $(9,10)$. Many reports have shown that curcumin has significant antiproliferative and apoptotic effects in a wide variety of tumor cell lines as well as the ability to inhibit tumorigenesis in mice $(11,12)$. This anticancer potential of curcumin is caused by the down-regulation of certain signal transduction pathways via transcription factors NF-kappa B, AP-1 and Egr-1, which are critical for tumor growth (13-15).

Recently, curcumin was shown to inhibit vascular endothelial cell proliferation in vitro and capillary tube formation in vivo (16-19). These studies demonstrated that the potent chemopreventive activity of curcumin may, in part, be derived from the direct inhibition of angiogenesis. However, the inhibition of hypoxia-induced angiogenesis by curcumin and underlying mechanism of inhibition have not been reported yet.

Here, we show that curcumin strongly down-regulates the HIF- $1 \alpha$ protein level and the functional activity of HIF-1 under hypoxic conditions. Curcumin potently inhibited hypoxia-induced mRNA and the protein expression of VEGF. Moreover, we found that curcumin suppresses hypoxia-stimulated angiogenic activities. These results demonstrate that curcumin inhibits hypoxia-induced angiogenesis by down-regulating HIF- $1 \alpha$ activity.

\section{Materials and methods}

Reagents and antibodies. Curcumin and N-acetyl-Leu-Leunorleucinal (LLnL) were purchased from Sigma (St. Louis, MO). Mouse monoclonal antibody against human HIF- $1 \alpha$ antibody and human $\alpha$-tubulin antibody were from BD biosciences (San Jose, CA) and biogenex (San Ramon, CA), 
respectively. VEGF antibody was purchased from Santa Cruz Biotechnology (Santa Cruz, CA).

Cell culture. HepG2 human hepatoblastoma cells and HEK 293 cells were maintained in DMEM supplemented with 10\% FBS and 1\% antibiotics (Invitrogen, Carlsbad, CA). Primary human umbilical vein endothelial cells (HUVECs) (passage 5-8) were grown on $0.3 \%$ gelatin-coated plates in M199 supplemented with $20 \% \mathrm{FBS}, 3 \mathrm{ng} / \mathrm{ml} \mathrm{bFGF}$ and $5 \mathrm{U} / \mathrm{ml}$ heparin. For hypoxic conditions, cells were incubated at $5 \%$ $\mathrm{CO}_{2}$ level with $1 \% \mathrm{O}_{2}$ balanced with $\mathrm{N}_{2}$ in a hypoxic chamber (Forma Scientific).

Western blot analysis. Proteins were separated by SDS/PAGE and transferred to a nitrocellulose membrane (Amersham Pharmacia Biotech, Arlington Heights, IL). The membrane was blocked with 5\% skim milk in phosphate-buffered saline containing $0.1 \%$ Tween-20 for $1 \mathrm{~h}$ at room temperature, incubated with the primary antibody at room temperature for $1 \mathrm{~h}$ or at $4^{\circ} \mathrm{C}$ overnight, followed by incubation with horseradish-conjugated antibody against rabbit or mouse immunoglobulins at room temperature for $50 \mathrm{~min}$, and was then developed by the ECL plus Western detection system (Amersham Pharmacia Biotech).

Reverse transcription-polymerase chain reaction (RT-PCR). Total RNA was isolated from cell cultures by a single-step procedure with TRI Reagent (Life Technologies, Gaithersburg, MD). cDNA was synthesized from $5 \mu \mathrm{g}$ of total RNA with 200 units of MMLV-RT (Promega, Madison, WI) and $500 \mathrm{ng}$ of oligo-dT primer. PCR reaction was performed on firststrand cDNA using the PCR reaction kit (Takara) and primer sets. Amplification by PCR was performed using an automated thermal cycler (Perkin-Elmer). Oligonucleotide primers for PCR were designed as follows: ß-actin, 5'-GACTACCTC ATGAAGATC-3' and 5'-GATCCACATCTGCTGGAA-3'; HIF-1 $\alpha, 5$ '-CAGAAGATACAAGTAGCCTC-3' and 5'-CTG CTGGAATACTGTAACTG-3'; VEGF, 5'-GAGAATTCGG CCTCCGAAACCATGAACTTTCTGT-3' and 5'-GAGCAT GCCCTCCTGCCCGGCTCACCGC-3'.

Transient transfection and luciferase assay. Plasmids $(5 \mu \mathrm{g})$ were transfected to $5 \times 10^{5}$ HEK 293 cells/60-mm dish, with proper recombination of effector plasmids, pSV40promoterEpoHRE-Luc and control plasmid pCMV-ß-gal and pBOShHIF- $1 \alpha$ and pBOS-hARNT using Lipofectamine reagent according to the instructions of the manufacturer (Invitrogen). These vectors were kindly provided by Dr Fujii-Kuriyama (Tohoku University, Japan) (20). After transfection, cells were harvested and extracts were prepared using reporter lysis buffer (Promega). Cell lysates were analyzed for luciferase activity using an assay kit (Promega) and luminometer (Turner Design, Sunnyvale, CA). Extracts were also assayed for ß-galactosidase enzyme and for protein concentration using a protein assay kit (Sigma). Each extract was assayed three times, and the mean RLU was corrected by values obtained from an extract prepared from empty vector-transfected cells. The relative luciferase activity was calculated as RLU/B-galactosidase.

Tube formation assay. Two hundred and fifty $\mu 1$ Matrigel (10 mg/ml) (Beckton-Dickinson, Franklin Lakes, NJ) was pipetted onto 24-well culture plates and polymerized for $30 \mathrm{~min}$ at $37^{\circ} \mathrm{C}$. HUVECs $\left(1 \times 10^{5}\right.$ cells $)$ were seeded on the surface of Matrigel. Curcumin was added and incubated for $24 \mathrm{~h}$ under hypoxic conditions. Morphologic change of cells was observed under a microscope and photographed at x40 magnification using ImagePro Plus software (Media Cybernetics, Silver Spring, MD).

Wounding migration assay. Wounding migration assay was performed as previously described (21). HUVECs were plated onto $0.3 \%$ gelatin-coated $60-\mathrm{mm}$ culture dishes. At $90 \%$ confluence, the endothelial monolayers were marked with an injury line and wounded $2 \mathrm{~mm}$ in width with a sterile razor blade. Plates were rinsed with serum-free medium to remove cellular debris. Fresh medium with curcumin and $1 \mathrm{mM}$ thymidine were then added. HUVECs were allowed to migrate for $24 \mathrm{~h}$ and rinsed with serum-free medium, and photographs were taken through an inverted microscope (x40). The number of cells that moved beyond the reference line was counted. The experiment was performed more than three times.

Chemoinvasion assay. Chemoinvasion assay was carried out by the method of Saiki et al (22). The lower and upper sides of $8 \mu \mathrm{m}$ porosity polycarbonate filters were coated with $0.5 \mathrm{mg} / \mathrm{ml}$ type I collagen and $0.5 \mathrm{mg} / \mathrm{ml}$ Matrigel, respectively. The lower compartment contained curcumin-treated media containing $0.1 \mathrm{mg} / \mathrm{ml}$ bovine serum albumin and HUVECs were placed in the upper part of a Transwell plate. Cell invasion was determined by counting whole cell numbers at single filter with optical microscopy at x40 magnification. The experiment was assayed more than three times with duplicate independent samples.

\section{Results}

Curcumin down-regulates HIF-1a protein levels. To investigate the effect of curcumin on the expression of HIF-1 $\alpha$, we treated HepG 2 cells with curcumin for $6 \mathrm{~h}$ under hypoxic conditions. As shown in Fig. 1A, curcumin down-regulated the protein level of HIF-1 $\alpha$ stabilized by hypoxia; but it did not affect the mRNA level of HIF-1 $\alpha$. This suggests that the stability of the HIF-1 $\alpha$ protein level is reduced by curcumin. To confirm the notion, we added LLnL, proteasome inhibitor, to HepG2 cells and checked the levels of the HIF-1 $\alpha$ protein. In the presence of LLnL, the HIF-1 $\alpha$ protein level decreased by curcumin was restored to the level of hypoxia-treated cells, indicating that the degradation of HIF-1 $\alpha$ by curcumin is probably proteasomedependent (Fig. 1B).

Curcumin inhibits transcriptional activation mediated by $H I F-1$. We then determined whether curcumin is involved in HIF-1 transcriptional activity using a luciferase reporter system, pSV40promoter-EpoHRE-Luc. Upon transient transfection of HIF-1 $\alpha$, ARNT and EpoHRE-Luc vectors, reporter activity was stimulated in cells exposed to $1 \% \mathrm{O}_{2}$ (Fig. 2A). However, curcumin was shown to decrease the transcriptional activity of HIF-1 in a dose-dependent manner. Furthermore, to evaluate whether curcumin modulates the hypoxia-response element (HRE)-containing gene, VEGF, we treated HepG2 cells with curcumin under hypoxic conditions. The mRNA and protein 
(A)

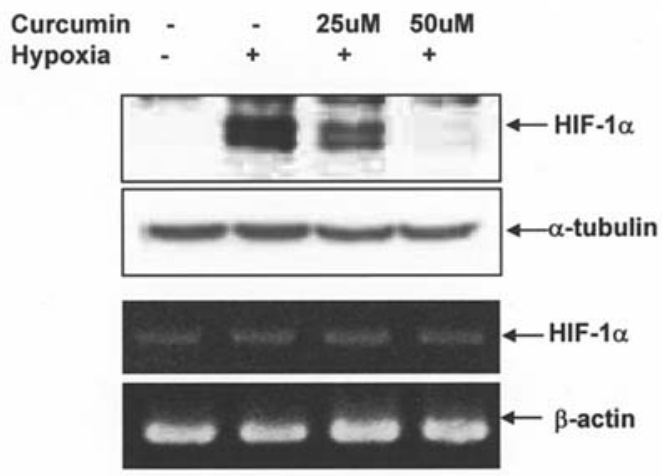

(B)

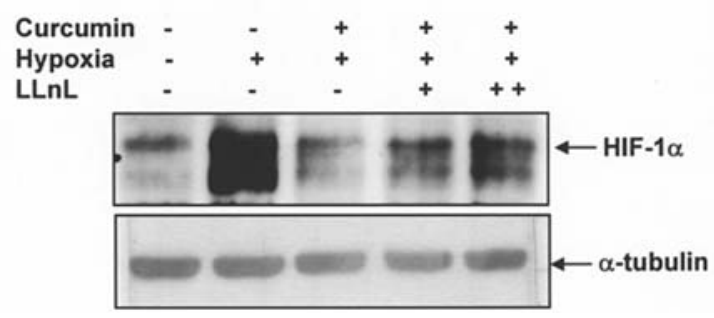

Figure 1. Curcumin decreases HIF-1 $\alpha$ protein levels. (A), HepG2 cells were incubated with or without curcumin at the indicated concentrations under $21 \% \mathrm{O}_{2}$ or $1 \% \mathrm{O}_{2}$ for $6 \mathrm{~h}$. Western blot (top two) and RT-PCR (bottom two) analyses against HIF- $1 \alpha$ were performed on total protein and RNA isolated from HepG2 cells treated as indicated. $\beta$-actin and $\alpha$-tubulin served as loading controls. (B), HepG2 cells were incubated with $21 \% \mathrm{O}_{2}$ or $1 \% \mathrm{O}_{2}$ for $6 \mathrm{~h}$ without or with $50 \mu \mathrm{M}$ curcumin. For the sample used in lanes 4 and 5 , cells were exposed to $35 \mu \mathrm{M} \mathrm{LLnL}$, proteasome inhibitor, for $2 \mathrm{~h}$ (lane 4) and $4 \mathrm{~h}$ (lane 5) respectively before harvest. All cells were harvested and total protein was isolated and used for immunoblot analysis using anti-HIF-1 $\alpha$ antibody and anti- $\alpha$-tubulin, respectively. $\alpha$-tubulin served as loading controls.

expression of VEGF were significantly down-regulated in curcumin-treated cells compared to hypoxia alone (Fig. 2B and C). These results suggest that curcumin negatively regulates the hypoxia-inducible transactivation function of HIF-1.

Inhibition of hypoxia-induced angiogenesis in vitro by curcumin. To investigate the direct effect of curcumin on vascular endothelial cells under hypoxic conditions, in vitro angiogenesis assays were conducted using HUVECs. Because it has been demonstrated that hypoxic conditions stimulate the vessel network formation of cultured endothelial cells $(23,24)$, we used hypoxia for the induction of angiogenesis. Curcumin was administered to HUVECs that were seeded on Matrigel beds $(10 \mathrm{mg} / \mathrm{ml})$, and incubated for $24 \mathrm{~h}$ under hypoxic conditions. HUVECs formed normally hollow tubes under normoxia but capillary network formation was further stimulated under hypoxia, resulting in elongated and robust tube-like structures. Curcumin strongly inhibited the hypoxiastimulated network by producing much foreshortened and severely broken tubes (Fig. 3A). Moreover, chemomigration assay showed that the mobility of HUVECs was significantly enhanced under hypoxic conditions similar to a previous report $(23,24)$, whereas the migrating ability of the cells was significantly reduced by curcumin (Fig. 3B). As another important property of angiogenesis, migrating endothelial
(A)

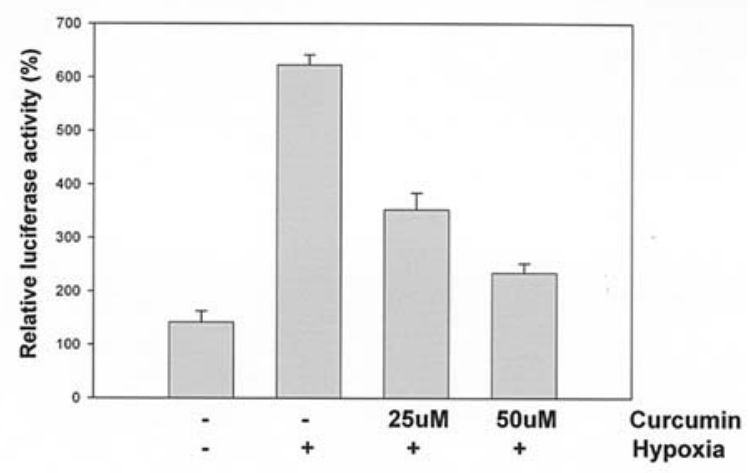

(B)

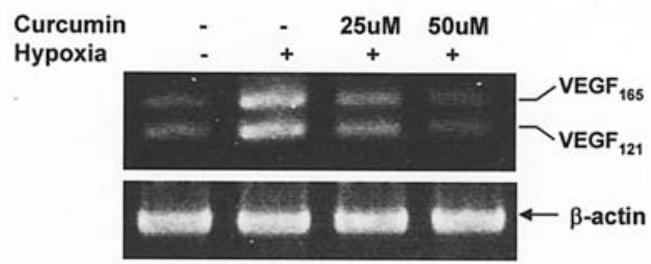

(C)

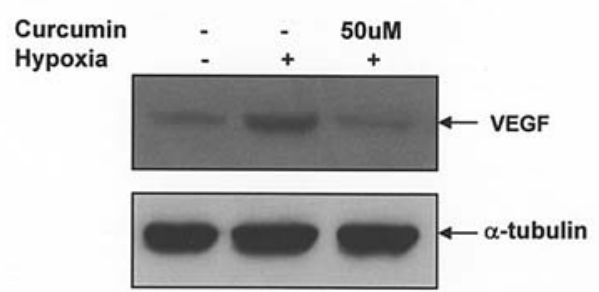

Figure 2. Curcumin suppresses the HIF-1-mediated transactivation function and hypoxia-induced VEGF expression. (A), HEK 293 cells were transfected with pSV40pro-EpoHRE-Luc $(1 \mu \mathrm{g})$, pBOS-hHIF- $1 \alpha(0.1 \mu \mathrm{g})$, and pBOS-hARNT $(0.1 \mu \mathrm{g})$. Transfected cells were incubated for $24 \mathrm{~h}$ at $21 \%$ $\mathrm{O}_{2}$, and then incubated at $21 \% \mathrm{O}_{2}$ or $1 \% \mathrm{O}_{2}$ for an additional $16 \mathrm{~h}$ with or without curcumin at the indicated concentrations. (B), HepG2 cells were exposed to $1 \% \mathrm{O}_{2}$ or $21 \% \mathrm{O}_{2}$ for $16 \mathrm{~h}$ in the absence or presence of curcumin at the indicated concentrations. RT-PCR analysis was performed using specific primer for VEGF and $B$-actin. (C), HepG2 cells were exposed to $1 \% \mathrm{O}_{2}$ or $21 \% \mathrm{O}_{2}$ for $16 \mathrm{~h}$ in the absence or presence of $50 \mu \mathrm{M}$ curcumin. Whole cell lysates were analyzed by Western blotting with VEGF-specific antibody. Western blot analysis with anti- $\alpha$-tubulin was performed as a control.

cells must break their basement membrane and transverse through it to form new blood vessels and hypoxia can stimulate endothelial cell invasion. Thus, the effect of curcumin on the vascular endothelial cell invasion was studied using a polycarbonate filter of transwell coated with the Matrigel. The HUVECs were placed in the filter and allowed to invade under normoxic or hypoxic conditions. As shown in Fig. 3C, curcumin significantly inhibited the hypoxia-stimulated invasiveness of HUVECs.

Loss of HIF-1 $\alpha$ in endothelial cells inhibits a number of important parameters of endothelia cell behavior during angiogenesis, resulting from the decreased level of hypoxiadriven VEGF (24). We therefore examined whether curcumin could influence the expression patterns of HIF- $1 \alpha$ and VEGF in hypoxic endothelial cells. As expected, curcumin suppressed 
(A)
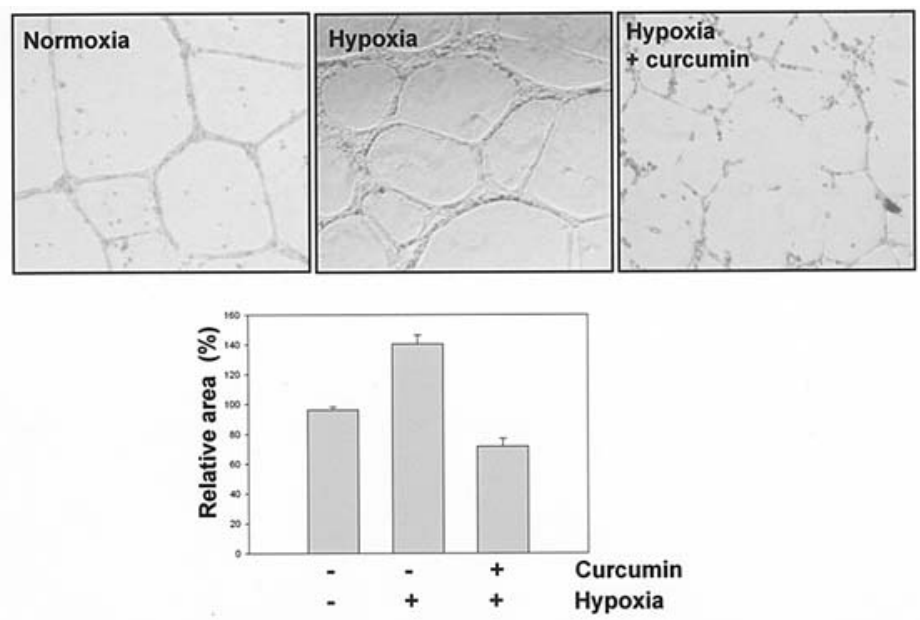

(B)

(C)
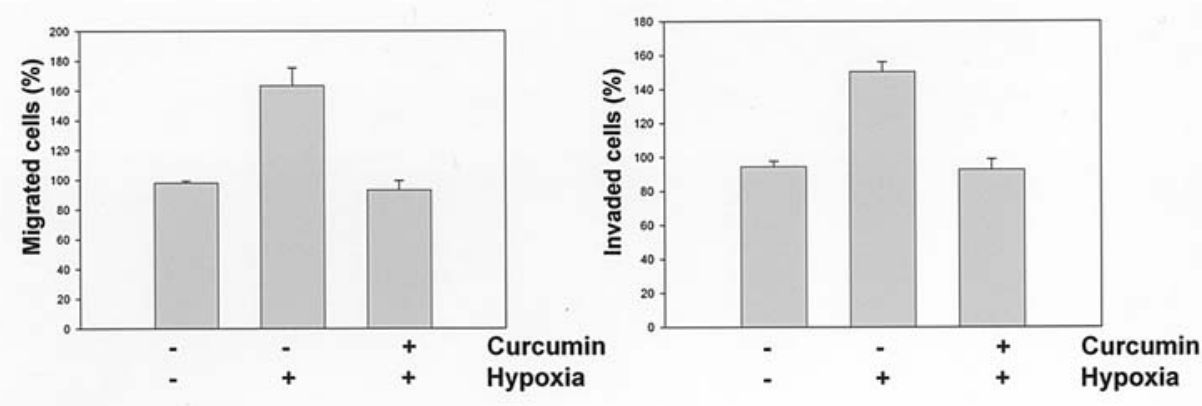

(D)

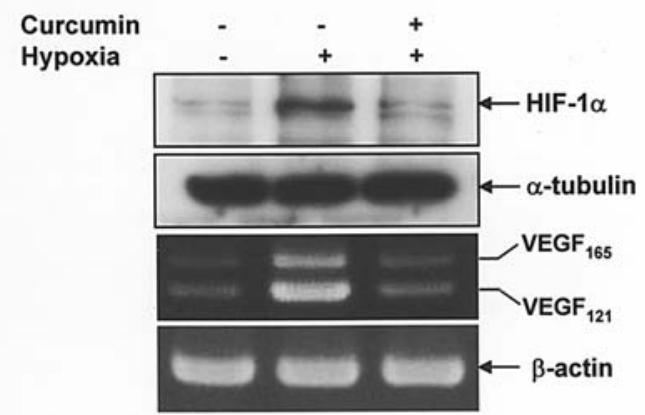

Figure 3. Inhibition of hypoxia-induced angiogenesis in vitro by curcumin. (A), HUVECs were incubated on the Matrigel with or without curcumin under $21 \% \mathrm{O}_{2}$ or $1 \% \mathrm{O}_{2}$ for $24 \mathrm{~h}$. The area covered by the tube network was quantitated using Image-Pro Plus software (below). (B), HUVECs were seeded on the gelatin-coated culture dish. At $90 \%$ confluence, the monolayers were wounded with a razor blade. Wounded cells were incubated with or without curcumin $(10 \mu \mathrm{M})$ under hypoxia for $24 \mathrm{~h}$. The number of HUVECs that moved beyond the reference line was counted. (C), HUVECs exposed to $1 \% \mathrm{O}_{2}$ or $21 \% \mathrm{O}_{2}$ in the absence or presence of $10 \mu \mathrm{M}$ curcumin were incubated on transwell chambers for $24 \mathrm{~h}$. The numbers of invaded cells were counted. All data (A-C) are expressed as percentage \pm SE from three different experiments with duplicates. (D), HUVECs were incubated with $21 \% \mathrm{O}_{2}$ or $1 \%$ O for $8 \mathrm{~h}$ with or without $10 \mu \mathrm{M}$ curcumin. Total proteins were analyzed by anti-HIF-1 $\alpha$ Western blotting (top two). RT-PCR was performed for VEGF with total RNA isolated from HUVECs under normoxia or hypoxia treated with $10 \mu \mathrm{M}$ curcumin (bottom two) for $16 \mathrm{~h}$. B-actin and $\alpha$-tubulin served as loading controls.

the HIF-1 $\alpha$ protein level and VEGF mRNA expression under hypoxia in endothelial cells (Fig. 3D). These results suggest that down-regulated HIF-1 $\alpha$ and VEGF by curcumin could inhibit the hypoxia-stimulated migration, invasion and tubular formation of endothelial cells.

\section{Discussion}

Curcumin, a well-known dietary pigment derived from the plant Curcuma longa L., has been studied as a chemopreventive agent in several cancer models (25) and entered into Phase I clinical trials for cancer chemoprevention by the
National Cancer Institute (26). Previous studies indicated that it efficiently induces antiproliferation and cell death in a variety of tumor cells $(27,28)$ and blocks angiogenic phenotypes in tumor and endothelial cells $(16,29)$. However, the molecular basis for the anti-angiogenic activity of curcumin and its target molecules has not yet been elucidated.

Aberrant expression of vascular endothelial growth factor (VEGF) and HIF-1 $\alpha$ protein, a transcription factor known to be a key regulator in hypoxia-induced angiogenesis, have been demonstrated to be associated with most hypoxic solid tumors $(30,31)$. Although curcumin is known to inhibit VEGF expression via either $\mathrm{AP}-1$ or $\mathrm{NF \kappa B}$ regulation in response to 
a variety of stimuli (32), the effect of curcumin on the hypoxiainduced VEGF expression and the regulation of HIF-1 $\alpha$ activity by curcumin are not well understood. In this study, we demonstrated that VEGF, a potent hypoxia-induced angiogenic factor, and HIF-1 $\alpha$, the transcription factor essential for VEGF transcriptional activation, can be regulated by curcumin in HepG2 hepatocellular carcinoma cells (Figs. 1 and 2). A recent report showed that curcumin induces proteasomal malfunction and accumulation of ubiquitinated protein such as p53 (33). However, contrasting results were reported by others (34), which have shown the down-regulation of cyclin D1 protein by curcumin through promoting proteolysis. From these reports, we speculated possible explanations for HIF- $1 \alpha$ destabilization by curcumin. It is possible that HIF- $1 \alpha$ protein stability may be inhibited indirectly by p53 levels elevated by curcumin. p53 interacts with HIF-1 $\alpha$ and limits hypoxiainduced expression of HIF-1 $\alpha$ by promoting its ubiquitinproteasome degradation (35). Another possibility is that destabilization of HIF- $1 \alpha$ protein is directly accelerated by activation of proteases in the proteasomal pathway. Of course, further investigations are necessary to clarify the precise destabilization mechanism of HIF-1 $\alpha$ protein under treatment with curcumin.

We further revealed that curcumin directly suppresses hypoxia-stimulated endothelial migration, invasion, and tube formation, which is also accompanied by decreased HIF-1 $\alpha$ and VEGF expression levels in curcumin-treated vascular endothelial cells (Fig. 3). A recent report showed that loss of hypoxia-responsive HIF-1 $\alpha$ in endothelial cells results in impaired angiogenesis. This impairment is a direct result of the disruption of an autocrine loop, acting through HIF-1 $\alpha$ regulation of hypoxia-induced VEGF expression (24). Therefore, we figured out that the functional HIF-1 $\alpha$ and its target, VEGF, play critical roles in endothelial cells as well as tumor cells in the process of hypoxia-driven tumor angiogenesis. Based on our observations, curcumin may have an HIF-1 $\alpha$ dependent tumor suppressive effect that is orchestrated by tumor and endothelial cells. To confirm this effect in vivo, we adopted highly angiogenic Lewis lung carcinoma (LLC) in mice as an in vivo animal angiogenesis model (21). In our experimental model system, curcumin significantly inhibited LLC tumor masses when they started to grow fast (data not shown); probably at the time when angiogenesis is actively performed, suggesting that curcumin may inhibit the initial angiogenic events that occurred inside the tumor. Our group has already reported that there were lots of microvessels, even in hypoxic regions of LLC tumor mass where HIF-1 $\alpha$ and VEGF were also highly expressed and detected by the hypoxic marker, pimonidazole (21). However, whether blood vessels in the hypoxic region regress in curcumin-treated tumor mass needs to be investigated.

In conclusion, curcumin down-regulates HIF- $1 \alpha$ protein levels and activity, and leads to the inhibition of VEGF gene expression. Furthermore, curcumin effectively blocks the hypoxia-stimulated angiogenesis of vascular endothelial cells.

\section{Acknowledgements}

This study was supported by the Creative Research Initiatives Program of the Ministry of Science and Technology (to K.-W.
K.), a Vascular System Research Center grant from KOSEF, and a Pusan National University Research Grant, 2004 (to M.-K. B.).

\section{References}

1. Vaupel P, Kallinowski F and Okunieff P: Blood flow, oxygen and nutrient supply, and metabolic microenvironment of human tumors. Cancer Res 49: 6449-6465, 1989.

2. Ryan HE, Poloni M, McNulty W, Elson D, Gassmann M, Arbeit JM and Johnson RS: Hypoxia-inducible factor-1alpha is a positive factor in solid tumor growth. Cancer Res 60: 4010-4015, 2000

3. Greco O, Marples B, Joiner MC and Scott SD: How to overcome (and exploit) tumor hypoxia for targeted gene therapy. $\mathrm{J}$ Cell Physiol 197: 312-325, 2003.

4. Brizel DM, Scully SP, Harrelson JM, Layfield LJ, Bean JM, Prosnitz LR and Dewhirst MW: Tumor oxygenation predicts for the likelihood of distant metastases in human soft tissue sarcoma. Cancer Res 56: 941-943, 1996.

5. Bergers $\mathrm{G}$ and Benjamin LE: Tumorigenesis and the angiogenic switch. Nat Rev Cancer 3: 401-410, 2003.

6. Vaupel P: The role of hypoxia-induced factors in tumor progression. Oncologist 9: 10-17, 2004.

7. Jeong JW, Bae MK, Ahn MY, Kim SH, Sohn TK, Bae MH, Yoo MA, Song EJ, Lee KJ and Kim KW: Regulation and destabilization of HIF-1alpha by ARD1-mediated acetylation. Cell 111: 709-720, 2002.

8. Ammon HP and Wahl MA: Pharmacology of Curcuma longa. Planta Med 57: 1-7, 1991

9. Ruby AJ, Kuttan G, Babu KD, Rajasekharan KN and Kuttan R: Anti-tumour and antioxidant activity of natural curcuminoids. Cancer Lett 94: 79-83, 1995.

10. Negi PS, Jayaprakasha GK, Jagan Mohan Rao L and Sakariah KK: Antibacterial activity of turmeric oil: a byproduct from curcumin manufacture. J Agric Food Chem 47: 4297-4300, 1999.

11. Huang MT, Lou YR, Ma W, Newmark HL, Reuhl KR and Conney AH: Inhibitory effects of dietary curcumin on forestomach, duodenal and colon carcinogenesis in mice. Cancer Res 54: 5841-5847, 1994

12. Khar A, Ali AM, Pardhasaradhi BV, Begum Z and Anjum R: Antitumor activity of curcumin is mediated through the induction of apoptosis in AK-5 tumor cells. FEBS Lett 445: 165-168, 1999 .

13. Singh S and Aggarwal BB: Activation of transcription factor NF-kappa is suppressed by curcumin. J Biol Chem 270: 24995-25000, 1995.

14. Huang TS, Lee SC and Lin J: Suppression of c-jun/AP-1 activation by an inhibitor of tumor promotion in mouse fibroblast cells. Proc Natl Acad Sci USA 88: 5292-5296, 1991.

15. Pendurthi UR and Rao LV: Suppression of transcription factor Egr-1 by curcumin. Thromb Res 97: 179-189, 2000.

16. Gururaj AE, Belakavadi M, Venkatesh DA, Marme D and Salimath BP: Molecular mechanisms of anti-angiogenic effect of curcumin. Biochem Biophys Res Commun 297: 934-942, 2002.

17. Mohan R, Sivak J, Ashton P, Russo LA, Pham BQ, Kasahara N, Raizman MB and Fini ME: Curcuminoids inhibit the angiogenic response stimulated by fibroblast growth factor-2, including expression of matrix metalloproteinase gelatinase B. J Biol Chem 275: 10405-10412, 2000.

18. Singh AK, Sidhu GS, Deepa T and Maheshwari RK: Curcumin inhibits the proliferation and cell cycle progression of human umbilical vein endothelial cell. Cancer Lett 107: 109-115, 1996.

19. Shim JS, Kim JH, Cho HY, Yum YN, Kim SH, Park HJ, Shim BS, Choi SH and Kwon HJ: Irreversible inhibition of CD13/aminopeptidase $\mathrm{N}$ by the antiangiogenic agent curcumin. Chem Biol 10: 695-704, 2003.

20. Ema M, Hirota K, Mimura J, Abe H, Yodoi J, Sogawa K, Poellinger L and Fujii-Kuriyama Y: Molecular mechanisms of transcription activation by HLF and HIFlalpha in response to hypoxia: their stabilization and redox signal-induced interaction with CBP/p300. EMBO J 18: 1905-1914, 1999.

21. Kim MS, Kwon HJ, Lee YM, Baek JH, Jang JE, Lee SW, Moon EJ, Kim HS, Lee SK, Chung HY, Kim CW and Kim KW: Histone deacetylases induce angiogenesis by negative regulation of tumor suppressor genes. Nat Med 7: 437-443, 2001. 
22. Saiki I, Fujii H, Yoneda J, Abe F, Nakajima M, Tsuruo T and Azuma I: Role of aminopeptidase N (CD13) in tumor-cell invasion and extracellular matrix degradation. Int J Cancer 54: 137-143, 1993.

23. Phillips PG, Birnby LM and Narendran A: Hypoxia induces capillary network formation in cultured bovine pulmonary microvessel endothelial cells. Am J Physiol 268: L789-L800, 1995.

24. Tang N, Wang L, Esko J, Giordano FJ, Huang Y, Gerber HP, Ferrara N and Johnson RS: Loss of HIF-1alpha in endothelial cells disrupts a hypoxia-driven VEGF autocrine loop necessary for tumorigenesis. Cancer Cell 6: 485-495, 2004.

25. Aggarwal BB, Kumar A and Bharti AC: Anticancer potential of curcumin: preclinical and clinical studies. Anticancer Res 23: 363-398, 2003.

26. Kelloff GJ, Crowell JA, Hawk ET, et al: Strategy and planning for chemopreventive drug development: clinical development plans II. J Cell Biochem 26 (suppl): 54-71, 1996.

27. Mehta K, Pantazis P, McQueen T and Aggarwal BB: Antiproliferative effect of curcumin (diferuloylmethane) against human breast tumor cell lines. Anticancer Drugs 8: 470-481, 1997.

28. Shim JS, Lee HJ, Park SS, Cha BG and Chang HR: Curcumininduced apoptosis of A-431 cells involves caspase-3 activation. J Biochem Mol Biol 34: 189-193, 2001.
29. Thaloor D, Singh AK, Sidhu GS, Prasad PV, Kleinman HK and Maheshwari RK: Inhibition of angiogenic differentiation of human umbilical vein endothelial cells by curcumin. Cell Growth Differ 9: 305-312, 1998.

30. Semenza GL: HIF-1: using two hands to flip the angiogenic switch. Cancer Metastasis Rev 19: 59-65, 2000

31. Richard DE, Berra E and Pouyssegur J: Angiogenesis: how a tumor adapts to hypoxia. Biochem Biophys Res Commun 266: 718-722, 1999.

32. Okamoto T, Yamagishi S, Inagaki Y, Amano S, Koga K, Abe R, Takeuchi M, Ohno S, Yoshimura A and Makita Z: Angiogenesis induced by advanced glycation end products and its prevention by cerivastatin. FASEB J 16: 1928-1930, 2002.

33. Jana NR, Dikshit P, Goswami A and Nukina N: Inhibition of proteasomal function by curcumin induces apoptosis through mitochondrial pathway. J Biol Chem 279: 11680-11685, 2004.

34. Mukhopadhyay A, Banerjee S, Stafford LJ, Xia C, Liu M and Aggarwal BB: Curcumin-induced suppression of cell proliferation correlates with down-regulation of cyclin D1 expression and CDK4-mediated retinoblastoma protein phosphorylation. Oncogene 21: 8852-8861, 2002.

35. Ravi R, Mookerjee B, Bhujwalla ZM, Sutter CH, Artemov D, Zeng Q, Dillehay LE, Madan A, Semenza GL and Bedi A: Regulation of tumor angiogenesis by p53-induced degradation of hypoxia-inducible factor 1alpha. Genes Dev 14: 34-44, 2000. 